\title{
Learning to Lead: Teaching the Millennial Nursing Student Leadership Skills in a Short-Term Immersion Study Abroad Program
}

\section{Antoinette Towle}

Southern Connecticut State University, Department of Nursing, 501 Crescent Street, New Haven, CT 06510, USA

\begin{abstract}
This paper presents the strategies used to teach millennial generation nursing students the leadership skills needed to provide quality and safe nursing care in the context of an experiential short-term study abroad program in Jamaica. To achieve this educational goal and to meet the requirements specific to the course, the program was built on a framework of two interrelated approaches: concept-based learning and cultural immersion. Cultural immersion was accomplished through carefully selected site visits, activities, and assignments. Through active-learning projects that used assessment, planning, and implementation, students were required to apply learned nursing knowledge and skills and to demonstrate essential nursing leadership skills. Students' experiences, reflections, and applications were assessed through formative and summative evaluation.
\end{abstract}

\section{Highlights}

- Mastering leadership skills involves concept-based learning and cultural immersion.

- Active-learning projects require students to apply learned knowledge and skills.

- Nursing leadership skills are best practiced through activelearning projects.

\section{Introduction}

Nursing is the nation's largest healthcare profession, with over 3.1 million registered nurses nationwide [1]. With the Affordable Care Act's expanding the need to care for more than 30 million newly insured citizens and the rapidly aging Baby Boomer population (individuals born between 1946 and 1964), there is an increasing demand for nurses. Government analysts project that over 581,500 new Registered Nurse (RN) jobs will be created by 2018. Nevertheless, other projections indicate that, by 2025, the U.S. nursing shortage will grow to over 260,000 RNs [2]. Even as healthcare continues to shift from hospital-based to more community-based primary care and other outpatient sites, federal projections indicate that the rising complexity of acute care will increase the need for RNs in hospitals by $36 \%$ by 2020 [3].

Currently, Baby Boomers comprise approximately $28 \%$ of the total U.S. population [4]. Approximately $37.3 \%$ of nurses who work in healthcare are part of this generation [5]. New nursing school graduates will need to replace roughly 573,000 hospital RNs who will retire over the next 15-20 years [5]. Taking their place will be the Millennial generation (individuals born in the early 1980s to the mid 2000s), who are the largest generation in the United States, comprising roughly one-third of the total population in 2013. With the anticipated need for nurses in the future, many Millennial students have chosen to enter the nursing profession. Buerhaus et al. [2] found a $62 \%$ increase in the number of 23- to 26-year-olds who became RNs between 2002 and 2009.

The purpose of this paper is to report on an experiential study abroad program in Jamaica program to teach nursing students the leadership skills required to provide quality and safe nursing care. As part of this purpose, the advantages of using two interrelated approaches, concept-based learning and cultural immersion, will be discussed.

\section{Literature Review}

To develop a leadership program for Millennial nursing students, a clear definition of leader and leadership, as these terms apply to nursing, is required. According to the American Nurses Association [6], nurse leaders help others to achieve their highest potential. The importance of effective leadership in healthcare has been emphasized by numerous authors, and nursing leadership is particularly important, as nursing is the largest discipline in healthcare [7]. Nursing leadership includes empowering others, facilitating learning, developing nursing knowledge, and working with and through others to achieve success [6]. According to Frandsen [8], a leader should possess "transformational" skills that are grounded in listening, acceptance, awareness, persuasion, foresight, and commitment to the growth of others, and building community within the organization through a shared vision and mission. Leadership qualities, particularly relationship skills, are not innate; they must be trained and developed [7]. This suggests the need for leadership development programs. Dwyer [9] believed that developing students' professional identity is also an important component of any nursing program and stated, "Nurses will continue to be devalued if there is nonprofessional identity and support" (p.389).

Leadership involves a set of skills that can be learned by training, perception, practice, and experience over time [10]. Good leaders seek development opportunities that will help them learn new skills [11]. Benner et al. [12] believe that nurses develop leadership skills and an understanding of patient care over time through a sound educational base as well as a multitude of experiences. New nurses will learn leadership skills from more experienced nurses through preceptor ships, mentoring, and collaborative work.

Leadership in nurses should be fostered throughout their education, not just at the end, when they make the transition to practice [7]. Many new graduates reported feeling inadequately prepared for leadership

"Corresponding Author: $\mathrm{Dr}$. Antoinette Towle, Southern Connecticut State University, Department of Nursing, 501 Crescent Street, New Haven, CT 06510, USA; E-mail: towlea1@southernct.edu

Citation: Towle A (2015) Learning to Lead: Teaching the Millennial Nursing Student Leadership Skills in a Short-Term Immersion Study Abroad Program. Int J Nurs Clin Pract 2: 160. doi: http://dx.doi.org/10.15344/2394-4978/2015/160

Copyright: (c) 2015 Towle et al. This is an open-access article distributed under the terms of the Creative Commons Attribution License, which permits unrestricted use, distribution, and reproduction in any medium, provided the original author and source are credited. 
and management roles [13]. Shortened clinical orientation, increased patient acuity, and increased nurse-to-patient ratios have left new graduates feeling unprepared for leadership roles in nursing practice [14]. Employers and nurse executives criticize nursing educational programs for not preparing new graduates for the realities of the workplace [12]

Middleton [15] found that active learning, which allows students to bring deeper learning to their conscience, is an effective means of learning about leadership in undergraduate students. Role-playing, simulation, and management-specific case studies and activities (including online and web-based modules focused on developing leadership and delegation skills) should be integrated throughout the curriculum, not just in the senior year [16]. Omoike et al. [17] believe that it is valuable is to create partnerships and collaboration between academia and hospitals to advance nursing leadership and support faculty creativity in the design, acceptance, and adoption of leadership and management activities. It is imperative that nursing faculty develop activities that support the new healthcare paradigm with its emphasis on building leadership and delegation skills and establishing the graduate nurse professional identity [18].

\section{Methodology}

This qualitative and descriptive study was conducted in Jamaica, which served as the location for an experiential learning program to teach Millennial generation nursing students the leadership skills required for the provision of quality and safe nursing care. Participants were expected to(a) utilize the expertise of the faculty, particularly in terms of nursing leadership; (b)actively engage in learning by applying previously learned subject-area content, knowledge, and skills; and (c) become totally immersed in a culture and healthcare system different from their own.

\section{Participants (Student and Faculty)}

Prior to participating in this program, students were required to be enrolled in a four-year Bachelor of Science in Nursing (BSN) program, successfully complete at least one semester in the BSN program, complete an application in which they state the reasons that they wish to participate in the study-abroad program, and obtain faculty advisor permission to attend. Only nursing students from the university where the researcher is employed were selected to participate. Participants included include nine Yearl students ( 8 females and 1 male) and eight Year 2 students (seven females and one male). All students were Millennials, between the ages of 19 and 29 , and Caucasian, with one student of Vietnamese descent. For both Years 1 and 2, the same experienced nursing faculty member led the program. The nursing faculty member's areas of expertise include nursing leadership, community health, and working with diverse populations. In Year 2, a master's in nursing graduate student, an experienced $\mathrm{RN}$, participated in the program.

\section{Program design}

The program was offered for two consecutive years during the spring semester break in March and was part of a two-credit special topic nursing elective course. All BSN students are required to complete two nursing elective courses prior to graduation and this course fulfilled one of the required electives. The program was designed to provide a minimum of 30 hours of classroom and fieldwork. Participants were required to attend three formal learning classroom periods prior to going abroad and two post-classroom periods following the trip.
The entire length of the study abroad program was seven days. Posttrip, participants were required to present their research findings to several nursing associations as well as to their peers.

To achieve the goal of mastering essential leadership skills as well as to meet the requirements specific to the course, the program was built on a framework of two interrelated approaches: conceptbased learning and cultural immersion. Concept-based learning involves a "big-picture context," with a transdisciplinary theme, which guides students to think about content and facts at a much deeper level [19]. Concept-based learning mandates more critical thinking at increasingly higher levels of Bloom's taxonomy. According to Erickson and Lanning [20], the concepts are universal, timeless, and abstract and move students toward higher levels of thinking. Cultural immersion, as defined by Rodriguez [21], is "the ability to see things from another point of view and evaluate situations not as American students (how would I feel in your place), but as local community members (how do you, the other, feel in your place)" (para. 2). Through the combination of cultural immersion and the implementation of designated projects, participants used subject-area content, knowledge, and skills, includingessential nursing leadership skills, to make critical thinking decisions.

Nursing students learned about the profession of nursing, including its history, goals, and codes of ethics. They were taught what distinguishes the practice of nurses from other healthcare professions. Strategies that promoted professional identity included participants' working daily in both the clinic and the community with other volunteers from a variety of disciplines. The Jamaican people waited each day to meet the participants and to welcome them, and participants felt heard, part of the team, valued, respected, and needed. Participants were required to usetheir previously learned knowledge, skill, and expertise as well as guidance from faculty to formulate a plan of care for their patients.

The pre-study-abroad classroom time was spent on activities that required participants to explore, reflect on, and gain knowledge of the country in which the program was based as well as to develop their own professional identity. Participants were required to conduct research on the country (Jamaica), including its people, economy, political arena, healthcare system, culture, diversity, leading healthcare concerns, and educational system. They also were required to complete a self-awareness leadership skill checklist and other assignments that involved outlining their goals, expectations, foreseen problems, and possible solutions. Discussion groups focused on exploration of the essential leadership skills needed to address possible problems identified. Role playing, concept mapping, discussing case studies, and comparing and contrasting viewpoints and ideas helped to facilitate learning.

The key nursingleadership concepts focused on were professionalism (e.g., role, behaviors, professional identity), effective communication, teamwork and collaboration, patient-family centered care (e.g., advocacy, cultural diversity), safety, and critical thinking (clinical judgment). These leadership skills were selected for novice nurses who were entering the field of nursing and are based on the AACN essentials of baccalaureate education for professional nursing practice and Quality and Safety Education for Nurses (QSEN) Competencies. Becoming a competent, proficient nursing leader requires continuous learning, experience, and practice, and the key nursing leadership skills identified became a starting point and a building block of leadership development. 
Cultural immersion was accomplished through carefully selected site visits, activities, and assignments. Participants lived and participated in the community and in cultural and religious events, ate native food, attended local schools, played with community children, and worked in the clinics and community hospitals. Each day prior to breakfast and after dinner, participants were required to meet as a group and reflect on the previous or current day's events. Participants' experiences, reflections, and applications were assessed through formative and summative evaluation.

\section{Results}

In the post-study-abroad class time (two-post classroom), participants discussed and reflected on what they learned as well as completed a standard post-leadership skill inventory. Participants identified creativity, flexibility, and effective communication as the top three leadership skills in which they experienced significant improvement. Participants created concept maps by identifying the key points learned during the experience. Due to participants' total immersion in the culture of the Jamaican people, the concept maps were extremely detailed and in-depth and portrayed an understanding of this population. Participants also were required to create a poster and Power Point presentation to share their research findings with several nursing associations as well as with their peers. During these presentations, participants discussed their sense of empowerment and the togetherness that they experienced throughout the program. They were able to identify each other's strengths and contributions to the program's success. In the program evaluation completed by participants, $100 \%$ stated that the program provided them with an opportunity to learn how to effectively communicate not only with each other but also with the Jamaican people. They also stated that they felt like a team of "real" nurses who were helping people.

\section{Discussion}

The key nursing leadership concepts that were identified, discussed, and focused on throughout the program were professionalism, effective communication, teamwork and collaboration, patientfamily centered care, safety, and critical thinking. This short-term immersion study-abroad program provided an excellent venue to learn, practice, and build on leadership skills. The program promoted critical thinking and clinical reasoning through reflective practice and understanding of patient-family experiences in an effort to motivate students to become change agents.

The people and the situations were real and provided a dynamic process that connected their education and clinical practice, leading to participants' self-reflection and professional growth. Although technology is a large part of the life of Millennials, in Jamaica, there wereno cell phones or computers. Participants were required to talk to each other and to their patients and families face to face.

The importance of patient-family centered care was reiterated throughout the participants' nursing education. Generally, nurses' work with patients in a healthcare setting removed from the patients and their families' immediate environment. The program provided the opportunity for the participants to become part of the patient and their family's environment. They learned firsthand the problems, conflicts, strengths, weaknesses, limitations, and family dynamics that could affect care. Participants needed to assess, plan, implement, and evaluate outcomes based on their experience with patients and their families in their own environment.
Safety is a basic human need to feel safe. The program personnel continually reviewed all safety measures with the participants, emphasizing the importance of always keeping safety a top priority, and participants were expected to adhere to all safety rules. As part of this focus, participants watched out for each other, traveled in pairs, and shared concerns with each other, all of which resulted in a sense of camaraderie.

Critical thinking involves identifying a problem, determining the best solution, and choosing the most effective method of reaching that solution. After executing a plan, critical thinkers reflect on a situation to determine whether the solution was effective or whether a great deal of time was spent on reflection and discussion, which provided the participants with an opportunity to explore and understand the rationale for treatment decisions and care.

\section{Conclusion}

Millennial nursing students are the future leaders' of our healthcare system. They will be in charge of making decisions regarding patient care. Thus, these nursing students must be given the opportunity to learn and to demonstrate leadership knowledge, skills, and attributes. Study-board programs provide nursing students with the opportunity to be immersed in a healthcare experience, thus enabling the development of a professional identity as a nurse, the learning of leadership concepts and skills, and the experiencing of leadership roles, with the support of experienced faculty and mentors.

The literature emphasizes the importance of building leadership skills in nursing students during nursing education. Yet, there is no agreed-upon set of leadership competencies in which students must be proficient before graduation, and there is no mandatory clinical experience for nursing students to build leadership skills. A shortterm immersion study-abroad program provides an opportunity for both learning and experiential activities that provide new nurses with the leadership skills needed to provide quality and safe nursing care.

\section{Competing Interests}

The authors have no competing interests with the work presented in this manuscript.

\section{References}

1. American Association of Colleges of Nursing (AACN) (2011) Nursing fact sheet.

2. Buerhaus PI, Auerbach DI, Staiger DO (2009) The recent surge in nurse employment: causes and implications. Health Aff (Millwood) 28: w657-668.

3. National Advisory Council on Nurse Education and Practice (1996) Report to the Secretary of the Department of Health and Human Services on the Basic Registered Nurse Workforce. U.S. Department of Health and Human Services, Division of Nursing, Washington, DC.

4. Atchison $\mathrm{H}$ (2015) Baby boomers: a healthcare crisis nears, Healthcare.

5. Barr P (2014) As baby boomers retire, new staffing models emerge. Hospital and Health Networks. American Hospital Association.

6. American Nurses Association (2015) Leadership.

7. Curtis EA, de Vries J, Sheerin FK (2011) Developing leadership in nursing: exploring core factors. Br J Nurs 20: 306-309.

8. Frandsen B (2014) Nursing Leadership Management and Leadership Styles [Booklet]. The American Association of Nurse Assessment Coordination, Denver, CO.

9. Dwyer D (2011) Experiences of registered nurses as managers and leaders in residential aged care facilities: a systematic review. Int $\mathrm{J}$ Evid Based Healthc 9: 388-402. 
Citation: Towle A (2015) Learning to Lead: Teaching the Millennial Nursing Student Leadership Skills in a Short-Term Immersion Study Abroad Program. Int J Nurs Clin Pract 2: 160. doi: http://dx.doi.org/10.15344/2394-4978/2015/160

10. Hyacinth B (2014) Are leaders born or made? A true story, Leadership and Management.

11. Huber D (2014) Leadership and Nursing Care Management. Elsevier, St Louis, MO.

12. Benner P, Sutphen M, Leonard V, Day L, Shulman LS (2009) Educating Nurses: A Call for Radical Transformation. Jossey-Bass, San Francisco.

13. Dyess S, Sherman R (2011) Developing the leadership skills of new graduates to influence practice environments: a novice nurse leadership program. Nurs Adm Q 35: 313-322.

14. Yoder-Wise PS (2012) Preparing tomorrow's service leaders: an educational challenge. Nurs Adm Q 36: 169-178.

15. Middleton R (2013) Active learning and leadership in an undergraduate curriculum: How effective is it for student learning and transition to practice? Nurse Educ Pract 13: 83-88.

16. Aduddell KA, Dorman GE (2010) The development of the next generation of nurse leaders. J Nurs Educ 49: 168-171.

17. Omoike O, Stratton KM, Brooks BA, Ohlson S, Storfjell JL, et al. (2011) Advancing nursing leadership: a model for program implementation and measurement. Nurs Adm Q 35: 323-332.

18. Mbewe C, Jones M (2015) Associate degree curricula adequately prepare nurses for leadership roles? Medsurg Nurs 24: 10-3.

19. Schill B, Howell L (2011) Concept-based learning. Science and Children 48: $40-45$.

20. Erickson L, Lanning LA (2013) Transitioning to Concept-Based Curriculum and Instruction: How to Bring Content and Process Together. Corwin Press, Thousand Oaks, CA.

21. Rodriguez K (2000) Cultural immersion achieving the elusive perspective shift. Transitions Abroad Magazine 23: 6.

22. Shalala D (2010) The Future of Nursing, Leading Change (Advancing Health Report). Robert Wood Johnson Foundation Initiative on the Future of Nursing, Institute of Medicine, National Academies Press, Washington, DC. 